\title{
Intermediate uveitis: pattern of etiology, complications, treatment and outcome in a tertiary academic center
}

\author{
Thomas Ness ${ }^{*}$ (D), Daniel Boehringer and Sonja Heinzelmann
}

\begin{abstract}
Background: Patients with intermediate uveitis (IU) represent a heterogenous group characterized by a wide spectrum of etiologies and regional differences. Aim of the study was to analyze the characteristics of patients with IU examined in an academic center in Germany.

Methods: We conducted a retrospective analysis of the clinical records of all patients with intermediate uveitis referred to the Eye Center, University of Freiburg from 2007 to 2014. Diagnosis followed the Standardization in Uveitis Nomenclature (SUN) criteria. Data analysis included: etiology of IU, demographics, complications, treatment and visual acuity.

Results: We identified 159 patients with intermediate uveitis during that period. Mean age at diagnosis was 35 years. Most are female (64\%), and the mean duration of IU was 6.1 years (range 1 month - 35 years). Etiology of IU was idiopathic in 59\%. Multiple sclerosis (MS) (20\%) and sarcoidosis (10\%) were frequent systemic causes of IU. Other etiologies including infectious diseases (tuberculosis, borreliosis) or immune-mediated conditions (eg, after vaccination) were present in $11 \%$. The pattern of complications included macular edema (CME) (36\%), cataract (24\%), secondary glaucoma (7\%), and epiretinal membrane formation (19\%). Periphlebitis and optic neuritis were more frequent in conjunction with MS. Treatment comprised local and systemic steroids, immunosuppressive agents, biologics, and surgery. Best corrected visual acuity was better than 20/25 in 60\% of the eyes after more than 10 years of follow-up.

Conclusions: In our German academic center, most IU cases were idiopathic or associated with MS or sarcoidosis. In contrast to other countries, infectious cases were rare. Patients' overall visual prognosis is favorable even when the duration of IU has been long and and despite numerous complications.
\end{abstract}

Keywords: Intermediate uveitis, Etiology, Systemic associations, Complications, Treatment

\section{Background}

Uveitis in general and especially intermediate uveitis (IU) fulfills the criteria as a rare disease, and the $\mathrm{Na}$ tional Institutes of Health $(\mathrm{NIH})$ defines it as such $[1,2]$. Uveitis experts standardized the nomenclature for uveitis (SUN) in 2005. According to these criteria, intermediate uveitis is defined as an intraocular inflammation mainly focused on the vitreous and peripheral retina [3, 4]. Intermediate uveitis accounts for $1.4-31 \%$ of all uveitis patients [1, 5-13]. The incidence of IU varies between

\footnotetext{
* Correspondence: thomas.ness@uniklinik-freiburg.de Eye Center, Medical Center, University of Freiburg, Faculty of Medicine, Killianstr. 5, 79106 Freiburg, Germany
}

$1.4-2 / 100.000[9,14,15]$. IU can be a sight-threatening disease and usually affects young adults $[4,9]$. It is potentially associated with infectious and noninfectious diseases. Infectious diseases that may cause IU are tuberculosis, leprosy, Lyme's disease, syphilis, toxocariasis, Whipple's disease, and others. There is wide variation depending on specific geographic and cultural factors $[4,5,12-14,16]$; eg, tuberculosis is more frequent in underdeveloped countries [17]. Associated systemic diseases are multiple sclerosis (MS), sarcoidosis and others $[4,9,18]$. Cases not of infectious origin or associated systemic disease are considered idiopathic. Clinical features are cellular 
Table 1

\begin{tabular}{|c|c|}
\hline \multicolumn{2}{|l|}{ Demographic data } \\
\hline Gender Female (n (\%)) & $102(64 \%)$ \\
\hline $\begin{array}{l}\text { Age at diagnosis (years) } \\
\text { (mean/SD/SEM/Cl) }\end{array}$ & $\begin{array}{l}\text { mean } 35.3 \\
\text { SD } 17.1 \\
\text { SEM } 1.35 \\
\mathrm{Cl} \pm 2.66\end{array}$ \\
\hline $\begin{array}{l}\text { Follow up (years) } \\
\text { (mean/SD/SEM/Cl) }\end{array}$ & $\begin{array}{l}\text { mean } 6.1 \\
\text { SD } 6.9 \\
\text { SEM } 0.55 \\
C I \pm 1.08\end{array}$ \\
\hline \multicolumn{2}{|l|}{ Etiology ( $\mathrm{n}=$ patients (\%)) } \\
\hline Idiopathic & $93(58.3 \%)$ \\
\hline MS & $31(19.5 \%)$ \\
\hline Sarcoidosis & $16(10 \%)$ \\
\hline Infectious & $6(4 \%)$ \\
\hline Miscellaneous & $13(8 \%)$ \\
\hline $\begin{array}{l}\text { Initial visual acuity (logMar) } \\
\text { (mean/SD/SEM/CI) } \\
\text { eyes }\end{array}$ & $\begin{array}{l}\text { mean } 0.2 \\
\text { SD } 0.43 \\
\text { SEM } 0.02 \\
\mathrm{Cl} \pm 0.05\end{array}$ \\
\hline $\begin{array}{l}\text { Final visual acuity } \\
\text { (logMar) } \\
\text { (mean/SD/SEM/Cl) } \\
\text { eyes }\end{array}$ & $\begin{array}{l}\text { mean } 0.14 \\
\text { SD } 0.33 \\
\text { SEM } 0.02 \\
\mathrm{Cl} \pm 0.04\end{array}$ \\
\hline $\begin{array}{l}\text { Initial visual acuity } \\
>20 / 25(\text { (n (\%)) }\end{array}$ & $211(66 \%)$ \\
\hline $\begin{array}{l}\text { Final visual acuity } \\
>20 / 25(n(\%))\end{array}$ & $241(75 \%)$ \\
\hline
\end{tabular}

inflammation of the vitreous, peripheral vascular sheathing, and the formation of snow balls or snow banks [4, 9]. The most common reason for loss of visual acuity is cystoid macular edema (CME). Other complications are cataract, epiretinal membranes, optic neuritis, and glaucoma $[4,9,14,16]$.
We conducted this study to analyze the demographic and clinical data of patients with IU in our academic center in Central Europe.

\section{Methods}

This was a retrospective study including all patients with intermediate uveitis examined at the Eye Center, University of Freiburg between 2007 and 2014. Intermediate uveitis was classified according to recommendations by the SUN working group [3].

Our study received institutional review board approval (EK Freiburg 19/15). Patient consent was not required as this was a retrospective, pseudoanonymous chart review. Patients diagnosed with any disorder other than intermediate uveitis were excluded. All patients were examined in a specialized uveitis center and treated in a multidisciplinary setting. If necessary, the appropriate specialists were consulted to determine any suspected underlying systemic or infectious disease.

In the case of sarcoidosis we collected chest radiographs, computer tomographies, bronchoalveolar lavage results, biopsies and laboratory data, if available. Diagnosis of infectious IU was based on serological testing and systemic manifestations, if applicable.

Data analysis included: etiology of IU, demographics, complications, treatment modalities, visual acuity and final outcome. Continous factors are presented as mean, standard deviation, standard error of the mean and confidence interval. Categorial data are presented as percentages. We used chi-sqare statistics for hypothesis testing. Change in visual acuity is presented as Box- and Whisker Plot.

All calculations were performed with the R-platform using only core functionality [19].

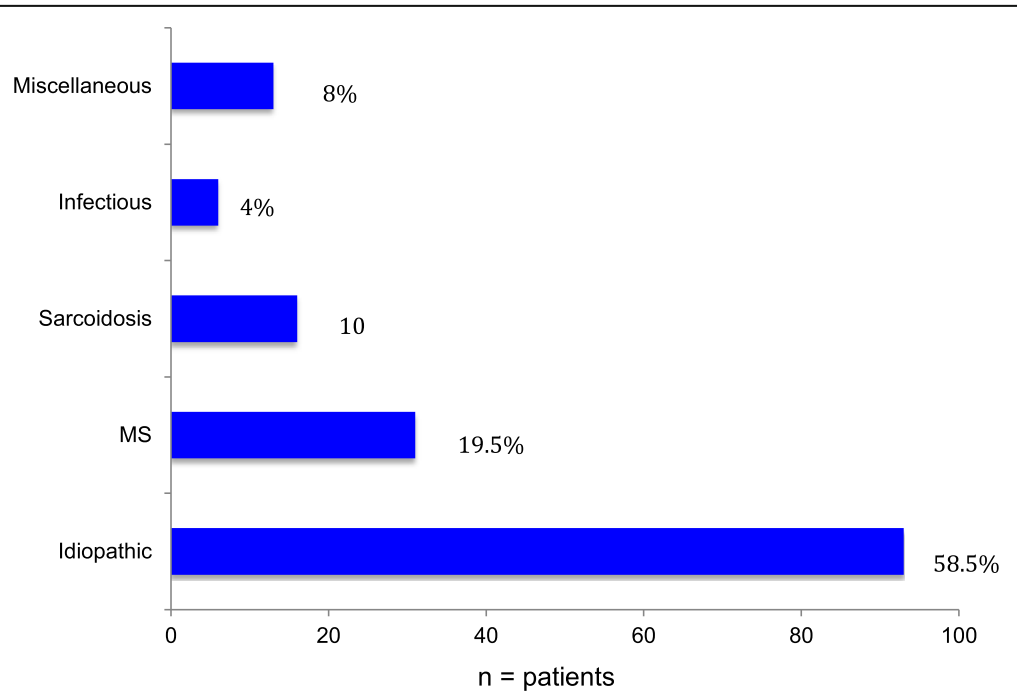

Fig. 1 Etiology of IU ( $n=$ number of patients) 


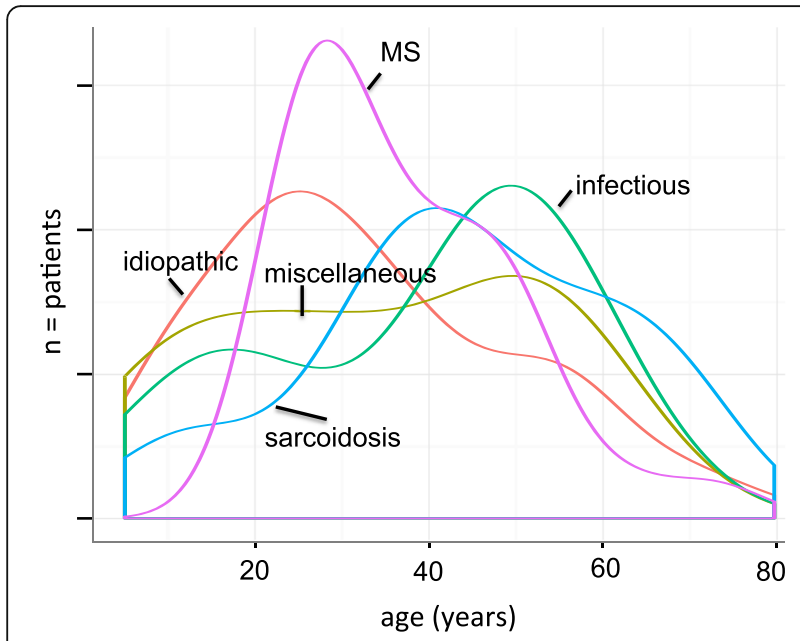

Fig. 2 Age distribution of the different etiologies of IU ( $n=$ number of patients)

\section{Results}

During the study period we identified 159 patients suffering from IU. Their mean age varied from 5 to 80 years (mean 35.2 years; standard deviation (SD) 17.1; standard error of the mean (SEM) 1.35; 95\% confidence intervall $(\mathrm{CI}) \pm 2.66)$. Mean follow-up was 6.1 years (SD 6.9; SEM 0.55; CI \pm 1.08 ) (Table 1).

Nearly two-thirds of these patients were female (64\%). The duration of IU at the date of inclusion in the study varied from 1 to 420 months (mean 73 months; SD 83; SEM 6.6; $C I \pm 12.9$ ). Regarding the etiology, $58.5 \%$ of the IU cases were idiopathic. Multiple sclerosis accounts for $19.5 \%$ and sarcoidosis for $10 \%$ of the patients $(n=16)$ (definite ocular sarcoidosis $n=2$, presumed ocular sarcoidosis $n=5$ and probable ocular sarcoidosis $n=9$ according to IWOS (International Workshop of ocular sarcoidosis) criteria [20]). Various infectious diseases like Lyme's disease $(n=5)$ or tuberculosis $(n=1)$ were detected in $4 \%$. None of these patients was immunocompromised. Other underlying diagnosis summarized under the term miscellaneous were made in $8 \%$ of the IU patients (Fig. 1). In detail, the miscellaneous group comprised cases with post immunization (FSME) $(n=1)$, juvenile idiopathic arthritis (JIA) $(n=3)$, psoriasis $(n=4)$, fibromyalgia $(n=1)$, Behcet's disease $(n=2)$; Crohn's disease $(n=1)$, and vemurafenib therapy $(n=1)$.

The age at diagnosis varied with the underlying origin of IU. Patients with idiopathic IU were the youngest (mean 32.9 years (SD 17.7; SEM 1.8; CI \pm 3.6 ), followed by the miscellaneous group (mean 34.7 years; SD 18.9; SEM 5.2; CI \pm 10.2 ). Patients with sarcoidosis (mean 44.1 years; SD 17.6; SEM 4.4; CI \pm 8.6 ), MS (mean 36.9 years; SD 12.6; SEM 2.3; $\mathrm{CI} \pm 4.4$ ) and infectious diseases (mean 39.0 years; SD 3.3; SEM 1.3; CI \pm 2.6 ) were older at the time of diagnosis. The distribution of age at the time of diagnosis is shown in Fig. 2. In patients with an infectious origin, there is a peak in patients under 20 years of age, and another in those about 50 years of age.

Only $22.5 \%$ of the IU patients required no systemic or parabulbar treatment. Most received systemic steroids (63.5\%), intravitreal steroids (10\%), or parabulbar steroids (13\%). Systemic immunosuppression (azathioprine, methotrexate, mycophenolate mofetil or cyclosporine A) was necessary in $24 \%$. Biologics were used in $10 \%$ (mainly

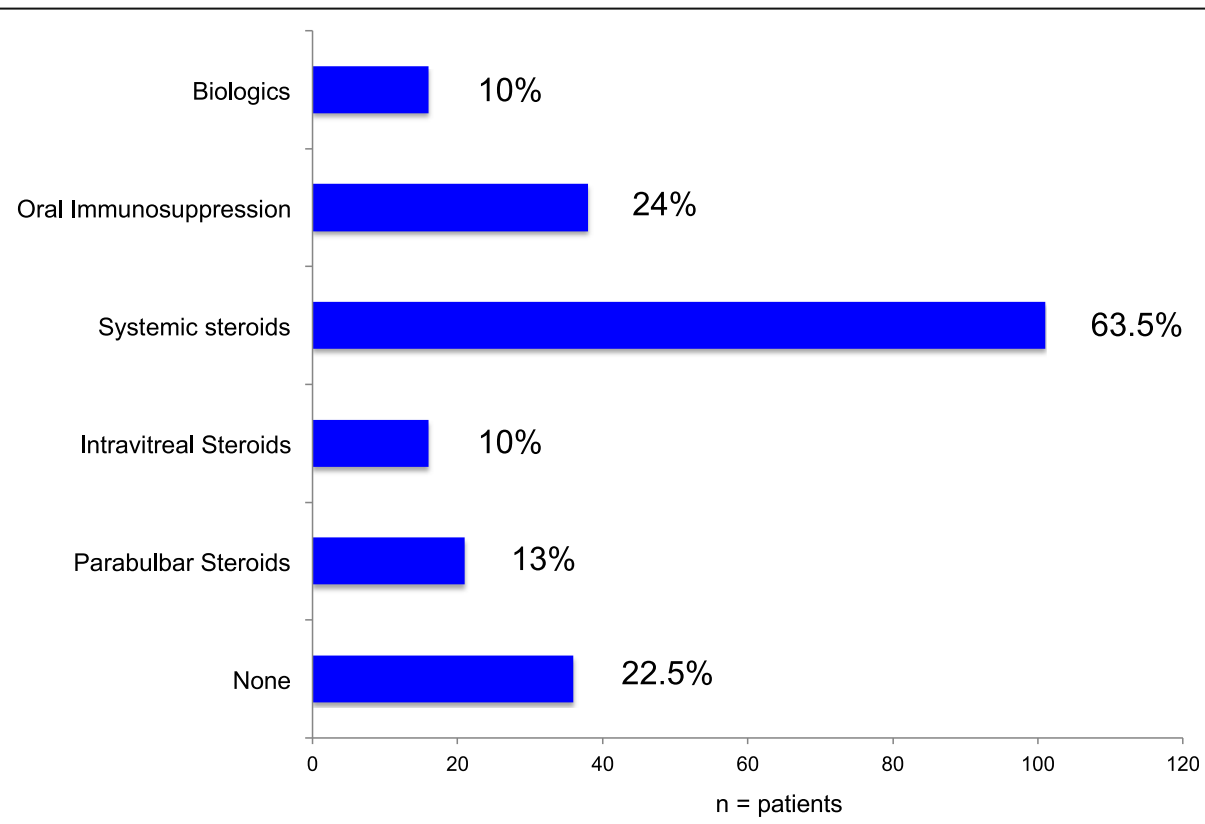

Fig. 3 Therapy of IU (oral immunosuppression: AZA, MTX, MMF, CSA) ( $n=$ number of patients) 
Table 2 Indication for therapy ( $n=$ patients)

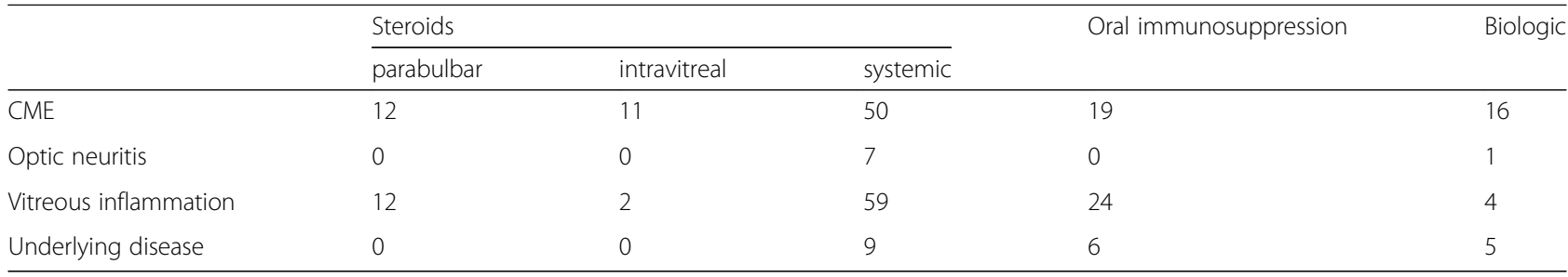

interferon alpha) (Fig. 3). The main indications for initiating therapy are summarised in Table 2 . Some patients got more than one therapy. Usually we started treatment with oral, parabulbar or intravitreal steroids. If there was no stable remission with less than $7.5 \mathrm{mg}$ prednisolon equivalent, an immunosuppressive or biologic agent was added.

A total of $62 \%$ of the IU patients developed at least one complication. Cystoid macular edema was the most frequent complication (36.5\%). Nearly a quarter suffered from cataract $(23.9 \%), 19 \%$ from epiretinal membrane, $5 \%$ from retinal detachment, and 7\% from glaucoma (Fig. 4). Periphlebitis and optic neuritis were significantly related to MS-associated IU ( $p<0.001$ Chi Square Test).

The overall prognosis was favorable. As Fig. 5 illustrates, visual acuity was stable over time in most patients. At the end of follow-up, $75 \%$ of the eyes had a best corrected visual acuity better than 20/25 (Table 1). As shown in Fig. 6, the percentage of eyes with visual acuity of $20 / 25$ or better was slightly decreasing with follow-up. After a follow up of at least 10 years more than $60 \%$ fulfilled this criterium.

\section{Discussion}

Our study demonstrates that IU in Central European patients is mostly non-infectious and idiopathic, requiring therapy in $80 \%$ of cases, and that it has an overall favorable prognosis. However, many patients experience at least one of many complications (eg. cataract, glaucoma, CME, epiretinal membrane). Many of these patients fulfilled the criteria for the older term pars planitis, which is restricted by SUN for "that subset of intermediate uveitis associated with snowbank or snowball formation in the absence of an associated infection or systemic disease" [3].

Like in our cohort, most other researchers have noted that IU usually affects young adults. The mean age at diagnosis varies between 22.6 and 33 years of age $[14,16,21-23]$. In contrast to other studies, we differentiated age by etiology. We observed a marked difference in age at diagnosis depending on the underlying disease. The youngest patients suffered from idiopathic IU, the oldest from infectious IU. In addition, we detected in conjunction with infectious IU a biphasic age distribution, with one peak in children and a second one in the fifth decade.

In Europe, the US and China, IU is usually idiopathic $[1,9,11,13,14,16]$. In contrast, in other parts of the world such as India, there is a marked proportion of infectious IU rising to 58\% [24]. In these countries, tuberculosis is a very common comorbidity; as the cause of IU in Europe and US it is rare [17]. On the other hand, MS is a frequent underlying disease in IU in our

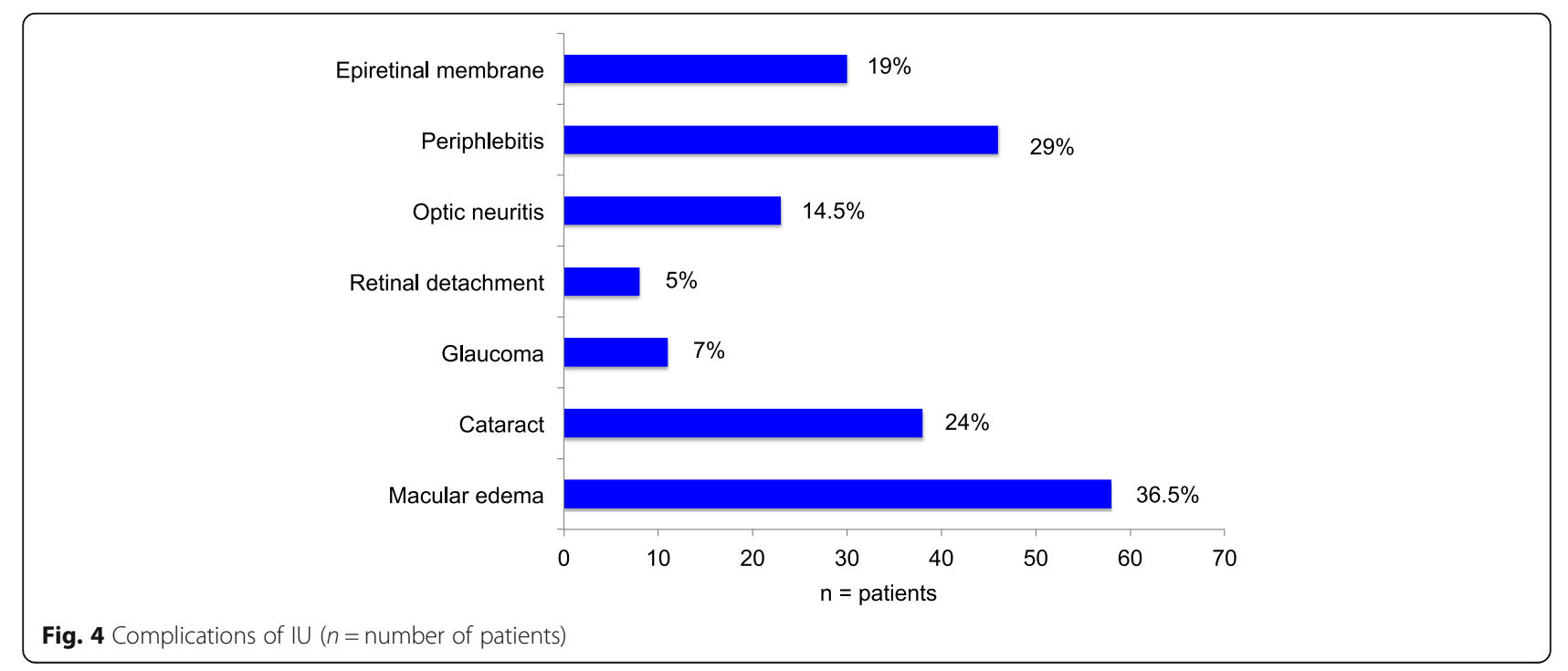




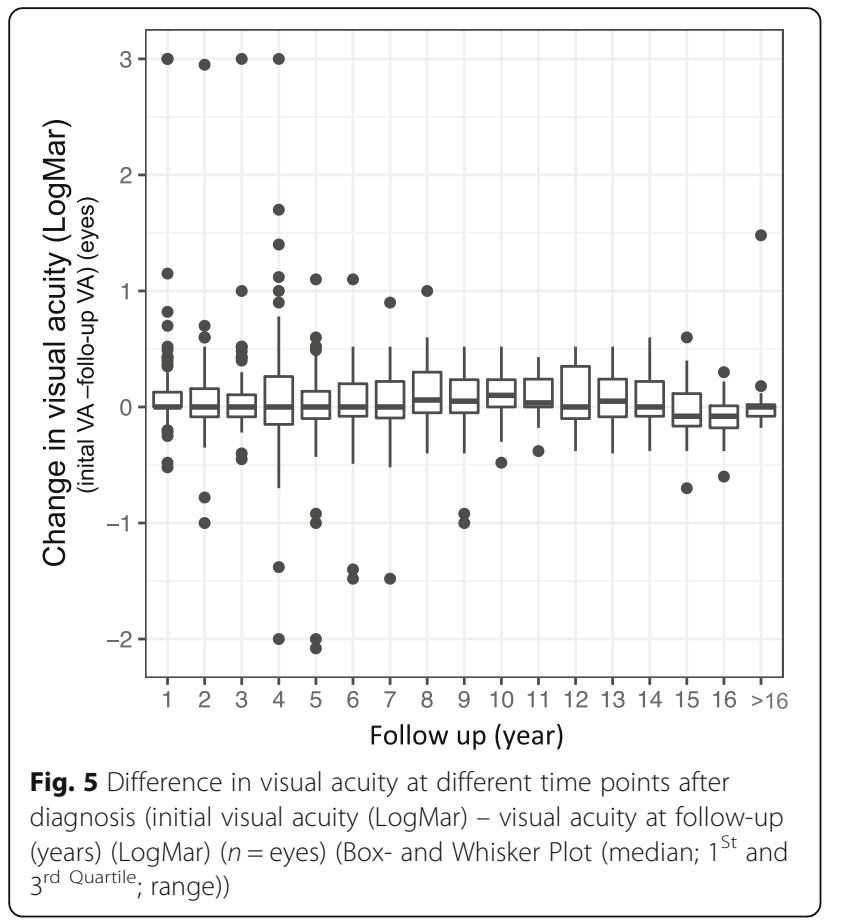

patients and in the US [14]. The proportion of MS in IU patients varies from 7 to $30.4 \%$ [1, 21, 25-31]. In our cohort, MS was very significantly associated with periphlebitis, a particular indication of IU. Others have observed the same [21,32]. Since IU might be the first manifestation of MS and early treatment seems to improve the overall prognosis, it is important to screen all IU patients for MS [33-35].

About $10 \%$ of our patients have sarcoidosis, a diagnosis that is also frequent elsewhere in the world $[1,9,11,16,31,36]$. We have found that soluble interleukin 2 receptor is a useful screening parameter [37].

Immunization as a cause of IU is currently under discussion. As described by several groups, FSME immunization may trigger IU in some patients [38-42]. JIA is associated with anterior uveitis. Our three cases suffered from IU and the pediatricians found no other underlying disease than JIA.

Many IU patients suffer from complications. The development of cataract, glaucoma, CME, epiretinal membrane formation, retinal detachment, periphlebitis or optic neuritis is similar worldwide $[4,9,10,14,30,43]$. Cataract and glaucoma might be caused by IU itself or by treatment of IU, especially with corticosteroids. There is ample evidence that CME and epiretinal membrane formation correlate with poor visual prognosis $[4,9,16]$.

As in the smaller study by Donaldson et al, nearly $2 / 3$ of our patients required therapy [14]. Main treatment indications in our series were CME or severe vitreous inflammation. Systemic, intraocular and parabulbar corticosteroids are the predominant therapeutic options. Only a quarter of our patients received immunosuppressive agents - more frequently than in China and the US $[8,14,16]$.

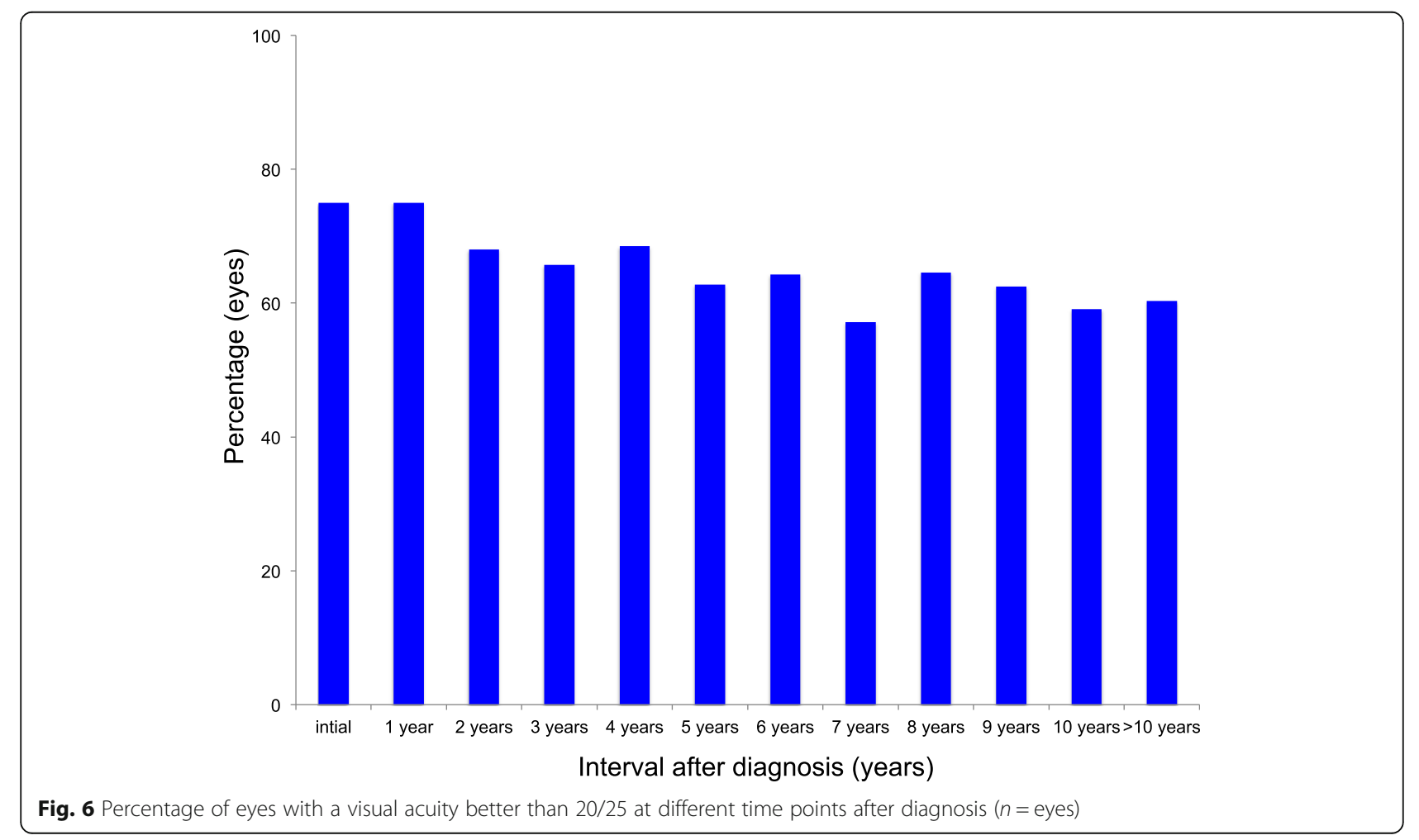


Regarding our cohort's MS patients: about 10\% received biologics, mainly interferon.

Despite the many complications, IU's overall prognosis is encouraging. Most patients have retained best corrected visual acuity of 20/40 or better [4,14,16,43]. The decrease of visual acuity during follow-up in our study might be biased by the fact, that patients with no complications and good visual acuity were lost for follow up. In our specialized center, those with complications were followed for a longer time.

Our study is limited by its retrospective character. Nevertheless, we report on a large number of patients and have delivered useful data for daily clinical practice.

\section{Conclusions}

In our German academic center, most IU cases were idiopathic or associated with MS or sarcoidosis. In contrast to other countries, infectious cases were rare. Patients' overall visual prognosis is favorable even when the duration of IU has been long and and despite numerous complications.

\section{Abbreviations}

CME: Cystoid macular edema; EK: Ethikkommission;

FSME: Frühsommermeningoenzephalitis; IU: Intermediate uveitis; JIA: Juvenile idiopathic arthritis; MS: Multiple sclerosis; NIH: National Institutes of Health; SUN: Standardization of uveitis nomenclature; US: United States

\section{Acknowledgements}

Not applicable.

\section{Funding}

The article processing charge was funded by the German Research Foundation (DFG) and the Albert Ludwigs University Freiburg in the funding programme Open Access Publishing.

\section{Availability of data and materials}

All data generated or analysed during this study are included in this published article. Nevertheless, the datasets during and/or analysed during the current study are available from the corresponding author on reasonable request.

\section{Authors' contributions}

The work presented here was carried out in collaboration between all authors. TN and SH defined the research theme. TN, DB, and SH analyzed the data and interpreted the results. TN wrote the paper. All authors have contributed to, seen and approved the manuscript.

\section{Competing interests}

TN; SH: Clinical studies with Novartis, Allergan, Abvie, Bayer, Santen; DB none.

\section{Consent for publication}

Not applicable.

\section{Ethics approval and consent to participate}

Our study received institutional review board approval (EK Freiburg 19/15). Ethik-Kommission der Albert-Ludwigs-Universität Freiburg, Engelberger Straße 21, 79106 Freiburg, Germany

\section{Publisher's Note}

Springer Nature remains neutral with regard to jurisdictional claims in published maps and institutional affiliations.
Received: 5 August 2016 Accepted: 19 April 2017

Published online: 27 April 2017

\section{References}

1. Barisani-Asenbauer T, Maca SM, Mejdoubi L, Emminger W, Machold K, Auer $\mathrm{H}$. Uveitis- a rare disease often associated with systemic diseases and infections- a systematic review of 2619 patients. Orphanet J Rare Dis. 2012;7:57.

2. Diseases Beginning With $U$ | Genetic and Rare Diseases Information Center (GARD) - an NCATS Program. [cited 2016 Feb 14]. Available from: https://rarediseases.info.nih.gov/gard/browse-by-first-letter/U. Accessed 23 Apr 2017.

3. Jabs DA, Nussenblatt RB, Rosenbaum JT. Standardization of uveitis nomenclature for reporting clinical data. Results of the First International Workshop. Am J Ophthalmol. 2005:140:509-16.

4. Bonfioli AA, Damico FM, Curi AL, Orefice F. Intermediate uveitis. Semin Ophthalmol. 2005;20:147-54

5. Chang JH-M, Wakefield D. Uveitis: a global perspective. Ocul Immunol Inflamm. 2002;10:263-79.

6. Khairallah M, Yahia SB, Ladjimi A, Messaoud R, Zaouali S, Attia S, et al Pattern of uveitis in a referral centre in Tunisia, North Africa. Eye Lond Engl. 2007;21:33-9.

7. Oruc S, Kaplan AD, Galen M, Kaplan HJ. Uveitis referral pattern in a Midwest University Eye Center. Ocul Immunol Inflamm. 2003:11:287-98.

8. Jones NP. The manchester uveitis clinic: the first 3000 patients, 2: uveitis manifestations, complications, medical and surgical management. Ocul Immunol Inflamm. 2015;23:127-34.

9. $\quad$ Babu BM, Rathinam SR. Intermediate uveitis. Indian J Ophthalmol. 2010;58: 21-7.

10. Bajwa A, Osmanzada D, Osmanzada S, Khan I, Patrie J, Xin W, et al. Epidemiology of uveitis in the mid-Atlantic United States. Clin Ophthalmol Auckl NZ. 2015;9:889-901.

11. Grajewski RS, Caramoy A, Frank KF, Rubbert-Roth A, Fätkenheuer G, Kirchhof B, et al. Spectrum of Uveitis in A German Tertiary Center: Review of 474 Consecutive Patients. Ocul Immunol Inflamm. 2015:1-7.

12. Wakabayashi T, Morimura Y, Miyamoto Y, Okada AA. Changing patterns of intraocular inflammatory disease in Japan. Ocul Immunol Inflamm. 2003;11:277-86

13. Yang $P$, Zhang Z, Zhou H, Li B, Huang X, Gao Y, et al. Clinical patterns and characteristics of uveitis in a tertiary center for uveitis in China. Curr Eye Res. 2005;30:943-8.

14. Donaldson MJ, Pulido JS, Herman DC, Diehl N, Hodge D. Pars planitis: a 20-years study of incidence, clinical features, and outcomes. Am J Ophthalmol. 2007;144:812-7.

15. Vadot E. Epidemiology of intermediate uveitis: a prospective study in Savoy. Dev Ophthalmol. 1992;23:33-4.

16. Chan CKM, Wu ZHY, Luk FOJ, Liu DTL, Fan AH, Lee VYW, et al. Clinical characteristics of intermediate uveitis in Chinese patients. Ocul Immunol Inflamm. 2013;21:71-6.

17. Shakarchi Fl. Ocular tuberculosis: current perspectives. Clin Ophthalmol Auckl NZ. 2015;9:2223-7.

18. Boskovich SA, Lowder CY, Meisler DM, Gutman FA. Systemic diseases associated with intermediate uveitis. Cleve Clin J Med. 1993:60:460-5.

19. R Core Team, R Foundation for Statistical Computing. R: A Language and Environment for Statistical Computing. Vienna; 2014. Available from: http://www.R-project.org. Accessed 23 Apr 2017

20. Herbort CP, Rao NA, Mochizuki M. International criteria for the diagnosis of ocular sarcoidosis: results of the first International Workshop On Ocular Sarcoidosis (IWOS). Ocul Immunol Inflamm. 2009:17:160-9.

21. Raja SC, Jabs DA, Dunn JP, Fekrat S, Machan CH, Marsh MJ, et al. Pars planitis: clinical features and class II HLA associations. Ophthalmology. 1999;106:594-9.

22. Henderly DE, Genstler AJ, Rao NA, Smith RE. Pars planitis. Trans Ophthalmol Soc U K. 1986;105(Pt 2):227-32.

23. Lauer AK, Smith JR, Robertson JE, Rosenbaum JT. Vitreous hemorrhage is a common complication of pediatric pars planitis. Ophthalmology. 2002;109:95-8.

24. Rathinam SR, Namperumalsamy P. Global variation and pattern changes in epidemiology of uveitis. Indian J Ophthalmol. 2007:55:173-83.

25. Messenger W, Hildebrandt L, Mackensen F, Suhler E, Becker M, Rosenbaum JT. Characterisation of uveitis in association with multiple sclerosis. Br J Ophthalmol. 2015;99:205-9. 
26. Biousse V, Trichet $C$, Bloch-Michel E, Roullet E. Multiple sclerosis associated with uveitis in two large clinic-based series. Neurology. 1999;52:179-81.

27. Le Scanff J, Sève P, Renoux C, Broussolle C, Confavreux C, Vukusic S. Uveitis associated with multiple sclerosis. Mult Scler Houndmills Basingstoke Engl. 2008;14:415-7.

28. Zein G, Berta A, Foster CS. Multiple sclerosis-associated uveitis. Ocul Immunol Inflamm. 2004;12:137-42.

29. Schmidt S, Wessels L, Augustin A, Klockgether T. Patients with Multiple Sclerosis and concomitant uveitis/periphlebitis retinae are not distinct from those without intraocular inflammation. J Neurol Sci. 2001;187:49-53.

30. Prieto JF, Dios E, Gutierrez JM, Mayo A, Calonge M, Herreras JM. Pars planitis: epidemiology, treatment, and association with multiple sclerosis. Ocul Immunol Inflamm. 2001;9:93-102.

31. Jakob E, Reuland MS, Mackensen F, Harsch N, Fleckenstein M, Lorenz HM, et al. Uveitis subtypes in a german interdisciplinary uveitis center-analysis of 1916 patients. J Rheumatol. 2009:36:127-36.

32. Petrushkin $\mathrm{H}$, Kidd D, Pavesio C. Intermediate uveitis and multiple sclerosis: to scan or not to scan. Br J Ophthalmol. 2015;99:1591-3.

33. Comi G, Martinelli V, Rodegher M, Moiola L, Leocani L, Bajenaru O, et al. Effects of early treatment with glatiramer acetate in patients with clinically isolated syndrome. Mult Scler Houndmills Basingstoke Engl. 2013;19:1074-83.

34. Freedman MS, Comi G, De Stefano N, Barkhof F, Polman CH, Uitdehaag BMJ, et al. Moving toward earlier treatment of multiple sclerosis: findings from a decade of clinical trials and implications for clinical practice. Mult Scler Relat Disord. 2014;3:147-55.

35. Bates D. Treatment effects of immunomodulatory therapies at different stages of multiple sclerosis in short-term trials. Neurology. 2011;76:514-25.

36. Tsui I, Kaines A, Schwartz S. Patterns of periphlebitis in intermediate uveitis using ultra wide field fluorescein angiography. Semin Ophthalmol. 2009;24:29-33.

37. Ness T, Hoffmann MM, Boehringer D, Heinzelmann S, Gundlach E. Soluble Interleukin 2 Receptor, Angiotensin Converting Enzyme, And Neopterin in Screening Ocular Sarcoidosis And Monitoring Disease Activity. PLoS One. 2016;11(1):e0147258. doi:10.1371/journal.pone.0147258.

38. Demicheli V, Debalini MG, Rivetti A. Vaccines for preventing tick-borne encephalitis. Cochrane Database Syst Rev. 2009;(1):CD000977. doi:10.1002/ 14651858.CD000977.pub2.

39. Grzeszczuk A, Sokolewicz-Bobrowska E, Prokopowicz D. Adverse reactions to tick-borne encephalitis vaccine: FSME-Immun. Infection. 1998;26:385-8.

40. Hofmann $\mathrm{H}$. After vaccination for tick-borne encephalitis must onset of neurologic disorders be expected? Wien Klin Wochenschr. 1995;107:509-15.

41. Doser AK, Hartmann K, Fleisch F, Kuhn M. Suspected neurological sideeffects of tick-borne meningoencephalitis vaccination: experiences of the swiss adverse drug reaction reporting center. Praxis. 2002;91:159-62.

42. Ness T, Hengel H. Adverse ocular effects of vaccinations. Ophthalmol Z Dtsch Ophthalmol Ges. 2016;113:615-22.

43. Malinowski SM, Pulido JS, Folk JC. Long-term visual outcome and complications associated with pars planitis. Ophthalmology. 1993;100:818-24.

\section{Submit your next manuscript to BioMed Central and we will help you at every step:}

- We accept pre-submission inquiries

- Our selector tool helps you to find the most relevant journal

- We provide round the clock customer support

- Convenient online submission

- Thorough peer review

- Inclusion in PubMed and all major indexing services

- Maximum visibility for your research

Submit your manuscript at www.biomedcentral.com/submit

) Biomed Central 